\title{
Erratum in Wilderness Environ Med. 29/1
}

Table 1 and Table 2 of the following article contained incorrect units.

Namal Rathnayaka RMMK, Ranathunga AN, Kularatne SAM, Rajapakse J, Ranasinghe S, Jayathunga R. Microangiopathic hemolytic anemia following three different species of humpnosed pit viper (genus: Hypnale) envenoming in
Sri Lanka. Wilderness Environ Med. 2018;29(1): 94-101.

On page 95, Table 1, and on page 98, Table 2, in Platelets and $\mathrm{RBC}$ count, the units are presented as $\mathrm{x} 10^{3} \mathrm{~g} \cdot \mathrm{uL} \mathrm{L}^{-1}$ and $\mathrm{x} 10^{6} \mathrm{~g} \cdot \mathrm{uL}^{-1}$, respectively. The units should be $\times 10^{3} \mu \mathrm{L}^{-1}$ and $\times 10^{6} \mu \mathrm{L}^{-1}$.

Corrected tables appear below.

Table 1. Laboratory findings of case 1 patient

\begin{tabular}{|c|c|c|c|c|c|c|c|c|c|c|c|}
\hline \multirow[b]{2}{*}{ Laboratory investigation } & \multicolumn{11}{|c|}{ Day } \\
\hline & 1 & 3 & 4 & 5 & 6 & 7 & 8 & 9 & 10 & 11 & 14 \\
\hline WBC $\left(\times 10^{3} \mu \mathrm{L}^{-1}\right)$ & 5.6 & 9.8 & & 7 & 8.1 & 8.9 & 7.7 & 7.3 & 7.7 & 9.6 & \\
\hline Neutrophils (\%) & 38.5 & 82.4 & & 72 & 63.7 & 75.2 & 78.5 & 61.4 & 71.4 & 77.3 & \\
\hline Lymphocytes (\%) & 52.6 & 9.9 & & 23 & 15.6 & 10.8 & 16.9 & 20.7 & 11.2 & 18.7 & \\
\hline Platelets $\left(\times 10^{3} \mu \mathrm{L}^{-1}\right)$ & 221 & 62 & & 34 & 26 & 63 & 91 & 129 & 261 & 319 & \\
\hline $\mathrm{Hb}\left(\mathrm{g} \cdot \mathrm{dL}^{-1}\right)$ & 12.1 & 12.3 & & 9.6 & 8.6 & 9 & 8.8 & 6.7 & 8.8 & 8.4 & \\
\hline $\operatorname{PCV}(\%)$ & 37.1 & 37.3 & & 29.3 & 26.2 & 26.9 & 25.9 & 20.6 & 27.2 & 24.2 & \\
\hline MCV (normal 80-95.5 fL) & 84.2 & 81.9 & & 81.9 & 81.7 & 82.1 & 82.2 & 83.9 & 82.6 & 79.8 & \\
\hline MCH (normal 27-31 Pg) & 27.6 & 26.9 & & 26.8 & 26.8 & 27.5 & 27.8 & 27.3 & 26.7 & 27.7 & \\
\hline MCHC (normal 33-37 $\mathrm{g} \cdot \mathrm{dL}^{-1}$ ) & 32.8 & 32.9 & & 32.7 & 32.8 & 33.5 & 33.8 & 32.6 & 32.3 & 34.7 & \\
\hline RBC count (normal $4-6 \times 10^{6} \mu \mathrm{L}^{-1}$ ) & 4.4 & 4.5 & & 3.5 & 3.2 & 3.2 & 3.1 & 2.4 & 3.2 & 3 & \\
\hline MPV (normal 7.8-11 fL) & 8.6 & 7.8 & & 9.5 & 9.3 & 10.4 & 9.2 & 7.6 & 8.6 & 7.5 & \\
\hline Serum creatinine $\left(\mu \mathrm{mol} \cdot \mathrm{L}^{-1}\right)$ & 87 & 358.4 & 454 & 419 & 598 & 582.1 & 423 & 532 & 296.2 & 235 & 128 \\
\hline Blood urea $\left(\mathrm{mmol} \cdot \mathrm{L}^{-1}\right)$ & 3.4 & 12.3 & 17.7 & 19 & 25.4 & 27.2 & 24.1 & 20.8 & 16.9 & 18.7 & 10.5 \\
\hline $\mathrm{Na}^{+}\left(\mathrm{mmol} \cdot \mathrm{L}^{-1}\right)$ & 137 & 140 & 135 & 134 & 134 & 132 & 126 & 131 & 137 & 128 & \\
\hline $\mathrm{K}^{+}\left(\mathrm{mmol} \cdot \mathrm{L}^{-1}\right)$ & 3.8 & 4.5 & 4.4 & 6.2 & 4.9 & 5.4 & 4.1 & 4.3 & 4.3 & 4 & \\
\hline PT (s) & $12.7 / 12$ & & & $12.7 / 12$ & $13.2 / 12$ & $13.6 / 12$ & $16 / 12$ & $13 / 12$ & & $14 / 12$ & \\
\hline INR & 1.06 & & & 1.06 & 1.10 & 1.14 & 1.34 & 1.08 & & 1.18 & \\
\hline APTT (s) & $27.6 / 30$ & & & $27.6 / 30$ & $28 / 30$ & $27.7 / 30$ & $30 / 30$ & $30 / 30$ & & $21 / 30$ & \\
\hline SGOT (AST) $\left[\mathrm{U} \cdot \mathrm{I}^{-1}\right]$ & 26 & & 31.3 & 34 & 32.8 & 65.5 & 103 & 73 & 24 & 19 & \\
\hline SGPT (ALT) $\left[\mathrm{U} \cdot \mathrm{I}^{-1}\right]$ & 19 & & 13.2 & 18 & 24.4 & 81.3 & 56 & 31 & 48.8 & 43 & \\
\hline Total bilirubin $\left(\mu \mathrm{mol} \cdot \mathrm{L}^{-1}\right)$ & & 49.5 & 56.7 & 55 & 41.5 & 17.7 & 10.8 & 7.9 & 6.71 & 6.7 & \\
\hline Direct bilirubin $\left(\mu \mathrm{mol} \cdot \mathrm{L}^{-1}\right)$ & & 10.5 & 16.4 & 14.1 & 12.3 & & & & & & \\
\hline $\operatorname{ALP}\left(\mathrm{U} \cdot \mathrm{I}^{-1}\right)$ & & 151.5 & 148 & & 182 & 195.7 & & & & & \\
\hline
\end{tabular}

WBC, white blood cells; $\mathrm{Hb}$, hemoglobin; $\mathrm{PCV}$, packed cell volume; $\mathrm{MCV}$, mean corpuscular volume; $\mathrm{MCH}$, mean corpuscular hemoglobin; MCHC, mean corpuscular hemoglobin concentration; $\mathrm{RBC}$, red blood cell; MPV, mean platelet volume; $\mathrm{Na}^{+}$, blood sodium level; $\mathrm{K}^{+}$, potassium; PT, prothrombin time; INR, international normalized ratio; APTT, activated partial thromboplastin time; SGOT, serum glutamic-oxaloacetic transaminase; AST, aspartate aminotransferase; SGPT, serum glutamic pyruvic transaminase; ALT, alanine aminotransferase; ALP, alkaline phosphatase. 
Table 2. Laboratory findings of case 2 and 3 patients

\begin{tabular}{|c|c|c|c|}
\hline \multirow[b]{2}{*}{ Laboratory investigation } & \multicolumn{2}{|c|}{ Case 2 patient } & \multirow{2}{*}{$\frac{\text { Case } 3 \text { patient }}{\text { Day } 1}$} \\
\hline & Day 1 & Day 2 & \\
\hline $\mathrm{WBC}\left(\times 10^{3} \mu \mathrm{L}^{-1}\right)$ & 7.4 & 7 & 5.8 \\
\hline Neutrophils (\%) & 74.2 & 46 & 36 \\
\hline Lymphocytes (\%) & 22.5 & 30.3 & 46.3 \\
\hline Platelets $\left(\times 10^{3} \mu \mathrm{L}^{-1}\right)$ & 239 & 302 & 399 \\
\hline $\mathrm{Hb}\left(\mathrm{g} \cdot \mathrm{dL}^{-1}\right)$ & 13 & 12.1 & 10 \\
\hline $\operatorname{PCV}(\%)$ & 41.4 & 26.9 & 33 \\
\hline MCV (normal 80-95.5 fL) & 86 & 87 & 80.3 \\
\hline MCH (normal 27-31 Pg) & 27.1 & 28.5 & 24.4 \\
\hline MCHC (normal 33-37 g.dL ${ }^{-1}$ ) & 31.5 & 32.8 & 30.4 \\
\hline RBC count (normal $4-6 \times 10^{6} \mu \mathrm{L}^{-1}$ ) & 4.8 & 4.2 & 4.1 \\
\hline MPV (normal 7.8-11 fL) & 7.8 & 8.5 & 8.1 \\
\hline Serum creatinine $\left(\mu \mathrm{mol} \cdot \mathrm{L}^{-1}\right)$ & 87 & 95.5 & 78 \\
\hline $\mathrm{Na}^{+}\left(\mathrm{mmol} \cdot \mathrm{L}^{-1}\right)$ & 146 & 141 & 143 \\
\hline $\mathrm{K}^{+}\left(\mathrm{mmol} \cdot \mathrm{L}^{-1}\right)$ & 4.6 & 3.8 & 3.7 \\
\hline PT (s) & $13 / 12$ & & $11 / 12$ \\
\hline INR & 1.08 & & 0.9 \\
\hline SGOT (AST) $\left[\mathrm{U} \cdot \mathrm{I}^{-1}\right]$ & 28 & & 59 \\
\hline SGPT (ALT) $\left[{\left.\mathrm{U} \cdot \mathrm{I}^{-1}\right]}^{-1}\right.$ & 40 & & 28 \\
\hline Total bilirubin $\left(\mu \mathrm{mol} \cdot \mathrm{L}^{-1}\right)$ & 26.3 & & 24.8 \\
\hline
\end{tabular}

WBC, white blood cells; Hb, hemoglobin; PCV, packed cell volume; MCV, mean corpuscular volume; MCH, mean corpuscular hemoglobin; $\mathrm{MCHC}$, mean corpuscular hemoglobin concentration; $\mathrm{RBC}$, red blood cell; MPV, mean platelet volume; $\mathrm{Na}^{+}$, blood sodium level; $\mathrm{K}^{+}$, potassium; PT, prothrombin time; INR, international normalized ratio; SGOT, serum glutamic-oxaloacetic transaminase; AST, aspartate aminotransferase; SGPT, serum glutamic pyruvic transaminase; ALT, alanine aminotransferase. 